\title{
Size matters: large spiny lobsters reduce the catchability of small conspecifics
}

\author{
Emma-Jade Tuffley ${ }^{1,2,3, *}$, Simon de Lestang ${ }^{2}$, Jason How ${ }^{2}$, Tim Langlois ${ }^{1,3}$ \\ ${ }^{1}$ School of Biological Sciences, The University of Western Australia, 35 Stirling Highway, Crawley, WA 6009, Australia \\ ${ }^{2}$ Aquatic Science and Assessment, Department of Primary Industries and Regional Development, 39 Northside Drive, \\ Hillarys, WA 6025, Australia
}

${ }^{3}$ The UWA Oceans Institute, Indian Ocean Marine Research Centre, Cnr. of Fairway and Service Road 4, Crawley, WA 6009, Australia

\begin{abstract}
Indices of lobster abundance and population demography are often derived from pot catch rate data and rely upon constant catchability. However, there is evidence in clawed lobsters, and some spiny lobsters, that catchability is affected by conspecifics present in pots, and that this effect is sex- and size-dependent. For the first time, this study investigated this effect in Panulirus cygnus, an economically important spiny lobster species endemic to Western Australia. Three studies: (1) aquaria trials, (2) pot seeding experiments, and (3) field surveys, were used to investigate how the presence of large male and female conspecifics influence catchability in smaller, immature P. cygnus. Large P. cygnus generally reduced the catchability of small conspecifics; large males by $26-33 \%$ and large females by $14-27 \%$. The effect of large females was complex and varied seasonally, dependent on the sex of the small lobster. Conspecific-related catchability should be a vital consideration when interpreting the results of pot-based surveys, especially if population demography changes. Analysis of the mean catch rate of large $P$. cygnus over the past $29 \mathrm{yr}$ indicates that fishery management changes have created significant variations in the abundance of large lobsters. This is likely to have affected the catchability of smaller lobsters, which will have implications for the use of time series catch rate data in the stock assessment and management of this fishery.
\end{abstract}

KEY WORDS: Panulirus cygnus · Spiny lobster $\cdot$ Catchability $\cdot$ Intraspecific interactions $\cdot$ Behaviour

\section{INTRODUCTION}

As there is currently no recognised method to age lobsters, stock assessment and management of lobster fisheries rely heavily upon representative and consistent size- and sex-structured abundance data (Punt et al. 2013). Due to the depths across which many lobster species live and their cryptic nature, pots (or traps) are typically the most cost-effective (Miller 1990) and potentially the most accurate (Tuffley et al. 2018) method to collect abundance and biological data on lobster populations. Using catch rates from pots to make inferences about the abundance, composition, or state of a stock is reliant on the assumption that

${ }^{*}$ Corresponding author:

emma-jade.tuffley@research.uwa.edu.au catchability remains constant between samples and individual lobsters, or that its variation can be accurately accounted for (Morgan 1974).

For a variety of lobster species, there is mounting evidence of size- and sex-dependent catchability related to conspecific interactions in and around pots. In clawed lobsters, underrepresentation of small animals in catch data is common and usually attributed to antagonistic encounters with larger animals in and around pots (Miller 1989, 1995, Addison 1995, Addison \& Bannister 1998). While antagonistic behaviours have been observed in numerous spiny lobster species, including the Japanese spiny lobster Panulirus japonicus (Hamasaki et al. 2018), the western rock

() The authors 2021. Open Access under Creative Commons by Attribution Licence. Use, distribution and reproduction are unrestricted. Authors and original publication must be credited. 
lobster P. cygnus (Cobb 1981), the southern rock lobster Jasus edwardsii (MacDiarmid 1989), and the Caribbean spiny lobster $P$. argus (Shabani et al. 2009), the possible impacts of these interactions on catch rates have been less well studied than in clawed lobsters.

Additionally, unlike clawed lobsters, spiny lobsters are gregarious, and therefore the effects of conspecific interactions on the catchability of spiny lobsters are potentially more complicated. Spiny lobsters preferentially select dens housing conspecifics in the wild (Childress \& Herrnkind 2001, Cobb 1981), and will choose to cohabit a den, rather than den alone, in experimental aquaria (Zimmer-Faust \& Spanier 1987). This behaviour is so pronounced in the Caribbean spiny lobster that it is exploited in the Florida spiny lobster fishery, where live juvenile $P$. argus are used as attractants in place of bait (Hunt 2008). Attraction between conspecifics may mean that captured spiny lobsters increase the catchability of subsequent lobsters (Miller 1990).

The only spiny lobster species to have received substantial investigation of conspecific-related catchability is the southern rock lobster $J$. edwardsii. In this species, catch rates of large and small individuals have been negatively correlated (Frusher \& Hoenig 2001, Ziegler et al. 2002), and large male and female lobsters inhibited small conspecifics from entering pots in pot seeding experiments (Ihde et al. 2006). These effects were seasonal and varied by sex, with the strongest inhibitory effect occurring between large and small females during the mating season. Similarly, research suggests den cohabitation patterns in the same species are also seasonal and dependent on sex. Large reproductive males were aggressive towards other males and rarely cohabited during the mating season, and likewise, cohabitation in large reproductive females was also lowest during this period (MacDiarmid 1994). These antisocial behaviours occurred exclusively within sexes, as rates of cohabitation between sexes were greatest during this period (MacDiarmid 1994). This increased cohabitation could lead to pot attraction, and correspondingly, there was some evidence of a seasonal attractant effect between large male and small female $J$. edwardsii in pot seeding experiments (Ihde et al. 2006).

Any deterrent or attractant effect of lobsters in and around pots will affect the catchability of subsequent lobsters. As these effects are often size- and sexspecific, spatial or temporal variation in population demography will cause variation in catchability, and subsequent variations in size-sex structured abundance data calculated from catch rates. Because fish- eries typically target specific size-sex classes, often large males in lobster fisheries, fishing pressure can lead to changes in population demography (Iacchei et al. 2005, Barrett et al. 2009, Bellchambers et al. 2017). For example, the removal of large J. edwardsii during the fishing season in South Australia has been shown to increase trap selectivity for small lobsters towards the end of the season (Frusher \& Hoenig 2001). This effect is so great that it masked declining stock recruitment over a $35 \mathrm{yr}$ period in that fishery (Frusher et al. 2003). Similarly, changes in fishery management, such as the adoption of more conservative targets or the implementation of fishery closures or no-take zones, can lead to increased abundances of the most targeted sex-size classes (Cox \& Hunt 2005, Babcock et al. 2007, Montgomery \& Liggins 2013). If large lobsters deter small lobsters, increased abundance of large individuals may reduce the catchability of smaller lobsters, which may lead to underestimating the abundance of small lobsters and potentially misleading interpretations around the performance of closed areas.

Catch per unit effort (CPUE) from pots is an important data source for the management of the P. cygnus fishery. P. cygnus is endemic to Western Australia, where it supports Australia's most valuable singlespecies fishery, the West Coast Rock Lobster Managed Fishery (WCRLMF), worth approximately AUD \$400 million annually (Gaughan \& Santoro 2018). Management of this fishery is governed by stock assessment models which use, in addition to other data sources, pot-based CPUE data from annual independent breeding stock surveys run by the state's fisheries department (the Department of Primary Industries and Regional Development; DPIRD). In the 2008-2009 fishing season, low levels of puerulus settlement prompted dramatic management changes, which led to a significant reduction in the fishery's annual catch (de Lestang et al. 2016, Caputi et al. 2018). This conservative level of fishing was maintained as the fishery adopted maximum economic yield as its target in the harvest strategy. As a result, the legal-sized biomass of this fishery approximately doubled over a $10 \mathrm{yr}$ period and is now the largest it has been for several decades (de Lestang et al. 2016, 2018, Caputi et al. 2018). In addition to an overall increase in biomass, these management changes have likely changed the demographics of the fishery, with a greater number of large lobsters being present. As there has been little research on the intraspecific interactions of P. cygnus in and around pots, it is unknown what effect the increased relative abundance of large animals will have on pot-based size- 
and sex-structured catch rate data used in stock assessment modelling.

This study explored how the presence of large conspecifics affects the catchability of smaller, immature $P$. cygnus using a weight-of-evidence approach based on 3 separate studies: (1) aquaria trials, (2) a seeding experiment, and (3) analysis of field survey data. If the catchability of small, immature P. cygnus is reduced by the presence of large conspecifics, it was expected that (1) cohabitation of small animals would be reduced in shelters containing large lobsters, (2) catch rates of small lobsters would be reduced in pots seeded with large lobsters, and (3) catch rates in pots which have captured large lobsters would be lower than those without large lobsters present. Finally, to assess how relevant these effects are for the stock assessment and management of the $P$. cygnus fishery, this study investigated whether the increase in biomass in the fishery corresponded to an increase in the catch rate of large animals. Twenty-eight years of lobster catch rate data, collected during DPIRD's independent breeding stock surveys (de Lestang et al. 2016), was analysed to investigate whether the average CPUE of large lobsters has changed over this period.

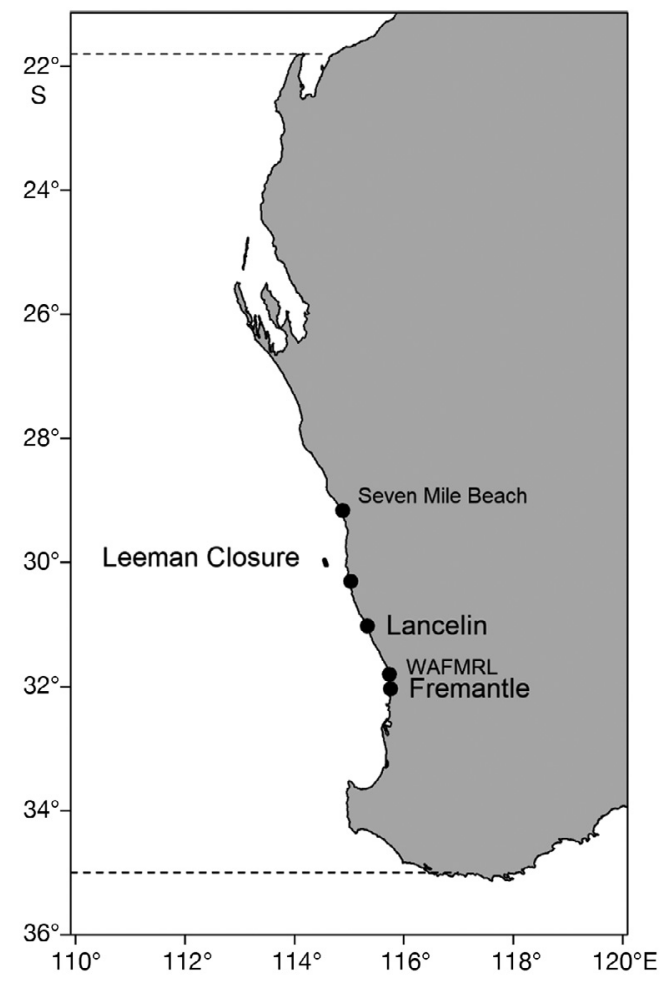

Fig. 1. Western Australian coastline and locations of Fremantle, WAFMRL, Leeman Research Closure, and Seven Mile Beach. Dotted line: northern and southern extent of the WCRLMF

\section{MATERIALS AND METHODS}

The R language for statistical computing (RStudio Team 2020) was used for all data manipulation (package 'dplyr'; Wickham et al. 2020), analysis, and graphing.

\subsection{Aquaria trials}

Aquaria trials were conducted between July and September 2017 at the Western Australian Fisheries and Marine Research Laboratories (WAFMRL), Western Australia (Fig. 1). Lobsters were collected onboard commercial lobster fishing vessels in Fremantle and Lancelin, Western Australia, and transported to WAFMRL in aerated tanks (Fig. 1). Lobsters were stored in a holding tank $(4.5 \times 1.5 \times 0.5 \mathrm{~m})$ containing numerous shelters for at least $7 \mathrm{~d}$ before the aquaria trials commenced, and when not participating in experiments. Lobsters were fed a diet of blue lip mussels Mytilus edulis, as well as various other local teleost fish and crustaceans, such that they were satiated throughout the trials. All tanks (holding and experimental) were supplied by a flowthrough water system, ensuring lobsters were subject to ambient seawater temperature and salinity. The holding tank was located undercover outside, and thus exposed to natural diurnal light cycles.

Trials were conducted in four $1200 \mathrm{l}$ rectangle aquariums. Two plastic shelters of equal dimensions $(40 \times 62 \times 26 \mathrm{~cm})$ were placed at either end (north and south) of each aquarium (Fig. 2a). Shelters were constructed of PVC containers, with an entrance at one end (Fig. 2b). The roofs of the shelters were constructed of rectangular pieces of grey industrial PVC which were slightly longer than the tubs, creating a 'veranda' over the entrance. Ambient seawater was pumped into the tanks at a rate of $150 \mathrm{l} \mathrm{h}^{-1}$ via 2 inflow pipes located at the back of each shelter, with the drain being located centrally. This ensured that any potential chemical cues released by lobsters inside the shelters were evenly drawn into the centre of the tanks. To ensure homogenous water movement within and between tanks, care was taken to ensure that all the 4 tanks were uniform and each tank was symmetrical and level. Artificial lighting was provided on a $12 \mathrm{~h}$ timer $(07: 00-19: 00 \mathrm{~h})$.

Lobsters were classified as either large mature males (LM; CL [carapace length] $\geq 100 \mathrm{~mm}$ ), large mature females (LF; CL $\geq 100 \mathrm{~mm}$ ), or small lobsters ( $\mathrm{SL} ; \mathrm{CL} \geq 76$ and $\leq 80 \mathrm{~mm}$ ). The size range of the small lobsters was selected so that the animals would be of 


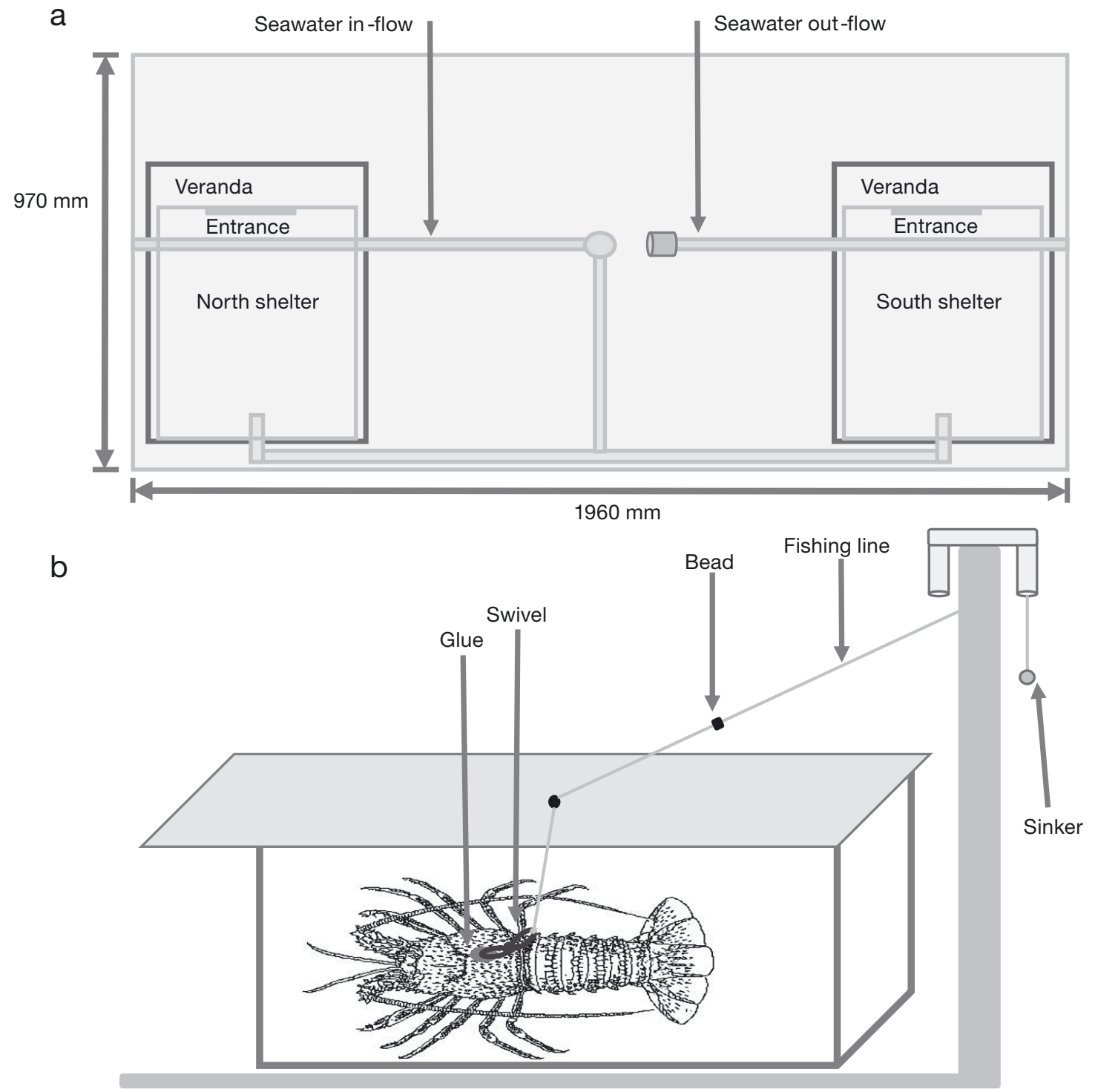

Fig. 2. Illustration of (a) the trial tanks and (b) a lobster tethered inside a shelter (lobster image credit: Tim Langlois)

legal size (CL $\geq 76 \mathrm{~mm}$ ) but still sexually immature (Melville-Smith \& de Lestang 2006). Each day, the 4 aquaria were randomly assigned one of 6 treatments (Table 1) consisting of one focal lobster, which was free to move about the tank and select a shelter in which to cohabit, and 2 stimulus lobsters, each tethered inside one of the 2 shelters (Fig. 2a). Stimulus lobsters were randomly assigned to the north or south shelters. Lobsters were tethered via fishing line, which was attached to a swivel glued to the lobster's carapace using a combination of Loctite and epoxy (Fig. 2b). The fishing line was threaded through a hole in the middle of the shelter lid and hung over the edge of the tank through PVC
Table 1. Treatments tested in the spiny lobster aquaria trials. LF: large female; LM: large male; SL: small lobster

\begin{tabular}{|lllll|}
\hline Treatment & Focal lobster & Large stimulus & Small stimulus \\
\hline 1 & $\mathrm{SL}=\mathrm{LF} / \mathrm{SL}$ & Small lobster & Large female & Small lobster \\
2 & $\mathrm{SL}=\mathrm{LM} / \mathrm{SL}$ & Small lobster & Large male & Small lobster \\
3 & $\mathrm{LF}=\mathrm{LM} / \mathrm{SL}$ & Large female & Large male & Small lobster \\
4 & $\mathrm{LF}=\mathrm{LF} / \mathrm{SL}$ & Large female & Large female & Small lobster \\
5 & $\mathrm{LM}=\mathrm{LF} / \mathrm{SL}$ & Large male & Large female & Small lobster \\
6 & $\mathrm{LM}=\mathrm{LM} / \mathrm{SL}$ & Large male & Large male & Small lobster \\
\hline
\end{tabular}

pipe (Fig. 2b). A large bead attached to the line limited the movement of the stimulus lobster, such that it could move about freely inside the shelter and interact with the focal lobster at the shelter entrance but 
was unable to exit the shelter. A small sinker attached to the loose end of the line took up slack as the lobster moved to the middle of the shelter, ensuring the lobster did not become entangled in the slack fishing line.

Stimulus lobsters were tethered in the experimental tanks approximately $3 \mathrm{~h}$ prior to the focal lobster entering the tank. This allowed them time to acclimate to the tank, recover from any stress related to tethering and for any chemical cues released during the tethering and tank transfer process to be flushed from the tanks. The focal lobster was released in the middle of the aquarium and left to select a shelter overnight. Transferring the focal lobsters from the holding tank to the experimental tanks may have also stressed the animals; however, as the focal lobsters had approximately $16 \mathrm{~h}$ to acclimate and select a shelter, there was no need to allow for an acclimation period. The location of the focal lobster was noted at 09:00 $\mathrm{h}$ the next day. The location was scored as either 1 -inside the shelter, 2-outside the shelter but displaying association with a shelter (i.e. in the veranda or near alongside the shelter) or 3 - no association with a shelter. All lobsters (focal and stimuli) were then returned to the holding tank, and the trial tanks were flushed with seawater for at least $4 \mathrm{~h}$ before the next trials began. Each lobster was only used as either the focal and stimulus lobster in each treatment once.

Treatments 1 and 2 (Table 1) tested whether small lobsters were affected by the presence of large lobsters. Because lobsters are gregarious and have been shown to preferentially cohabit, placing a small, immature lobster in the 'control' shelter meant the shelters were theoretically equally attractive as they both contained a lobster with which to cohabit, and only the shelter containing the large stimulus lobster was influenced by the size and sex of the animal. Treatments 3, 4, 5 and 6 (Table 1) tested whether large lobsters displayed any preference when presented with large and small lobsters with which to cohabit. This would elucidate whether deterrent effects were 1-way (i.e. large lobsters deter small, but small have no effect on large) or 2-way (i.e. large lobsters deter small, and small lobsters deter large).

Trials in which stimulus lobsters broke their tether were considered unsuccessful and were removed from the analysis. Only trials in which the focal lobster showed an association with a shelter (i.e. scored 1 or 2) were included. In accordance with animal ethics permit requirements, results were continually monitored so that trials could be concluded as quickly as possible to (1) avoid possible habituation which might impact the results of the study, and (2) avoid the unnecessary collection of additional lobsters from the wild. Cumulative curves, graphing the rolling average proportion of focal lobsters sheltering with the large stimulus lobster, assessed the progress of the trials. A stabilization of results indicated that additional replicates would have little effect on the outcome. The timing of this stabilization was used to determine when trials could cease. A binomial test of given proportions (Wilson 1927) was used to test whether the proportion of focal lobsters sheltering with the large stimulus lobster was significantly different from the null hypothesis of no preference $(50 \%)$ in each treatment. A difference from 0.5 in the proportion of animals sheltering with the large lobster would indicate the effect of the large animal.

\subsection{Seeding experiment}

Pot-seeding field experiments were conducted at Seven Mile Beach, Western Australia (Fig. 1), over 3 consecutive nights (10-13 September 2019) coinciding with the peak mating season of Panulirus cygnus. Seven Mile Beach is known to hold an abundant juvenile lobster population. Fourteen sites of 'good lobster habitat' were selected based upon previous surveys and underwater visual assessment. At each site, 2 lobster pots were fished within $2 \mathrm{~m}$ of each other, to ensure they were fishing the same group/ den of lobsters. Meshed, recreational-sized lobster pots were used, as they are known to capture a large range of lobster sizes, including juveniles, as well as accurately sample sites of variable abundance (see Tuffley et al. 2018 for a description of these pots and analysis of their appropriateness). Before setting, one pot was 'seeded' with one large female lobster (CL $\geq$ $100 \mathrm{~mm}$ ), with 2 wooden battens placed parallel over the entrance to prevent the lobster from escaping. The other ('blank') pot also had 2 wooden battens placed parallel across the entrance but was left empty to serve as a control. All pots were baited with approximately $1 \mathrm{~kg}$ of blue mackerel Scomber australasicus. Pairs of pots were fished overnight and retrieved between 06:30 and 12:00 $\mathrm{h}$ the next day. Upon retrieving the pots, the biological information of all captured lobsters was recorded, including CL, sex, reproductive state, and any damage to the animal, before they were returned to the site of capture. Damage to the pot was also recorded, as well as the presence of other animals, i.e. fish, octopus, or sharks, which may have impacted the pot's catchability. Bait baskets were thoroughly cleaned of any remaining 
bait and refilled with fresh bait. Pots were then reset at the same site.

To maximise statistical power with consideration to the experimental design, testing the influence of large lobsters on undersize catch rate was limited to one sex in the field experiments. Large females were selected as they had the smallest and least significant effect in the aquaria trails (see below) and therefore represented the most conservative option. As such, any effect of large females in the field would likely indicate a similar but stronger effect by large males. Large female lobsters were collected from Fremantle and Lancelin, Western Australia, and held at WAFMRL in the same holding tank under the same conditions as the lobsters in the aquaria trials. These females were already mated upon collection, as they all had spermatophores (tar-spots) on their sternum.

Pots whose catch may have been compromised (i.e. predators present, broken battens or dead lobsters present) were removed from the analysis. There is a latitudinal reduction in size at sexual maturity across the fishery, for both male and female lobsters (Melville-Smith \& de Lestang 2006). While males $\leq 80 \mathrm{~mm}$ were still likely immature, some females in this size range at Seven Mile Beach may have been mature. To ensure the analysis only considered the catch of immature females, only non-setose females (a biological indication of immaturity) $\leq 80 \mathrm{~mm}$ were considered. There were too few immature but legalsized lobsters at Seven Mile Beach to limit the analysis to those $\geq 76 \mathrm{~mm} \mathrm{CL}$, so no minimum CL value was set. As replication was at the site level, only sites at which both treatments were successfully fished were analysed.

A paired $t$-test compared the number of small immature lobsters caught in each treatment. Data was square root transformed to fit the assumption of normality. Square root transformation was selected based on the slope of log standard deviation against log mean of the 2 samples (Clarke \& Warwick 1994), and confirmed through visual assessment. To calculate the effect of the large female on the catchability of the seeded pots, the following equation was used:

$$
C_{\mathrm{LT}}=B_{\mathrm{L}} q \alpha_{\mathrm{T}}
$$

where $C_{\mathrm{LT}}$ is the catch at site (L) in treatment (T) (seeded or control), $B_{\mathrm{L}}$ is the biomass at the site, $q$ is the catchability of a small lobster (assumed to be equal across locations), and $\alpha_{\mathrm{T}}$ is the catchability scalar in treatment $(\mathrm{T})$. The catchability scalar of the control pot, $\alpha_{\text {control, }}$ will be equal to 1 , i.e. when a pot does not have a seeded lobster present there is no scalar on $q$. Therefore:

$$
\alpha_{\text {seed }}=C_{\text {seed }} / C_{\text {control }}
$$

The catchability scalar of the seed pot, $\alpha_{\text {seed, was }}$ calculated for each set of pot lifts and the mean calculated.

To test whether the presence of the large female affected the catch rates of small males and females differently, the proportions of small males and the proportions of small females caught in the seeded pots at each site were compared using a paired $t$-test. As above, the data was square root transformed, with normal distribution and homogeneity of variance confirmed through visual assessment.

To confirm that any potential differences in catch rates between the treatments were not the result of seeded pots reaching their upper-biomass limits or pot saturation (for an explanation of pot saturation, see Miller 1990), catches of each pot, including the seeded lobster, were converted into biomass via the length:weight ratio equation outlined in de Lestang et al. (2018) and compared.

\subsection{Survey data}

Time series pot catch rate data were obtained from annual independent stock surveys at The Leeman Research Closure (Fig. 1). The closure is a 3900 ha $(6 \times 2$ nautical miles) area in the middle of the WCRLMF, which has been closed to rock lobster fishing since 2011 (Fig. 1). The closure was surveyed annually between 2008 and 2016, with fishing occurring over 10 consecutive days during the new moon between midSeptember and early November each year to coincide with peak spawning season. Standard-sized commercial fishing pots with closed escape gaps (to retain undersized lobsters) were fished over 2 nights (2 d soak period) on the same GPS locations each year. Upon retrieval, all captured lobsters were measured (CL), and sex, reproductive state, and shell/appendage damage were recorded, along with the associated pot location (latitude/longitude).

Pots with compromised catchability (e.g. the presence of a predator, broken battens or deceased lobsters) were removed. As the expected effect of large lobsters on small lobster catch rates (a 15-25\% reduction; see Section 3.1) would be difficult to discern in pots with low catches, data was filtered to only include pots with catches of 5 or more lobsters. A generalised additive model (GAM; Wood 2017) was used to investigate how the presence of (1) no large lobsters, (2) large male lobsters (CL: $\geq 100 \mathrm{~mm}$ ), (3) large female lobsters (CL: $\geq 100 \mathrm{~mm}$ ), and (4) both 
large male and female lobsters impacted the catch rates of small, immature lobsters. Immaturity was allocated according to the same criteria as the field experiments above. Catches of small male and female lobsters were modelled both together and separately to assess whether large lobsters impacted small males and females differently.

A negative binomial error distribution was used to model this count data, as initial analysis using a Poisson distribution indicated overdispersion in the ratio of deviance and the residual degrees of freedom (Crawley 2002). Latitude and longitude were incorporated into the model as a smooth interaction term to account for spatial dependency of small lobster biomass, as previous research has indicated possible habitat segregation of size classes (Bellchambers et al. 2010). Year $(n=9)$ was also incorporated as a smooth function to account for any variations in juvenile biomass due to emigration and immigration across years. Therefore, catch rate was defined as:

$$
C_{\mathrm{LYT}}=B_{\mathrm{LY}} q \alpha_{\mathrm{T}}
$$

where $C_{\mathrm{LYT}}$ is the catch per pot at a location (L), in year $(\mathrm{Y})$, in treatment $(\mathrm{T})$, and treatment = no large lobsters (0), one or more large males (1), one or more large females (2), and one or more large males and females (3). $B_{\mathrm{LY}}$ is the biomass at the location in each year (Y), $q$ is the catchability of a small lobster (assumed to be equal across locations and years), and $\alpha_{\mathrm{T}}$ is the catchability scalar, with $\alpha_{0}=1$. Therefore:

$$
\begin{aligned}
& \alpha_{1}=C_{1} / C_{0} \\
& \alpha_{2}=C_{2} / C_{0} \\
& \alpha_{3}=C_{3} / C_{0}
\end{aligned}
$$

\subsection{Large lobster catch rate}

Catch rates of large lobsters were obtained from independent breeding stock surveys at 5 locations along the west Australian coast (Fremantle, Lancelin, Jurien, Dongara and Kalbarri) from 1992-2020. These surveys followed the same methodology as the independent field surveys above.

Marginal means from a generalised linear model was used to calculate the mean annual catch rate of large male and female lobsters ( $\geq 100 \mathrm{~mm})$, whilst accounting for heterogeneity in sampling of the various locations each year (location was treated as an additive factor). Prior to undertaking the modelling, raw data were tested for normality (Shapiro-Wilk) and homogeneity of variance (Levene's) and transformed $(\log (x+1))$ where necessary.

\section{RESULTS}

\subsection{Aquaria trials}

A total of 179 replicate trials were conducted, of which 28 were removed due to the stimulus lobster breaking free, and one because the focal lobster showed no association with either shelter (scored as '3'), resulting in 150 'successful' trials; 25 of each treatment. This level of replication saw the proportion sheltering/associating with the large stimulus lobster plateau (Fig. S1 in the Supplement at www.int-res. com/articles/suppl/m666p099_supp.pdf), and trials were concluded. The vast majority of replicates $(83 \%$; $\mathrm{n}=125$ ) resulted in the focal lobster sheltering inside a shelter (scored as ' 1 ') with only $17 \%(n=25)$ being associated with a shelter (scored as ' 2 ').

Small lobsters sheltered with large males in only $24 \%$ of trials (Fig. 3; SL $=$ LM/SL, $p=0.016$ ), indicating a $26 \%$ reduction from the null hypothesis of no preference $(50 \%)$. While not significant at the $95 \%$ confidence limit ( $p=0.11)$, there was a tendency for small lobsters to avoid large females, with only $36 \%$ of the small lobsters choosing to shelter with the large female (Fig. 3; SL = LF/SL), a $14 \%$ reduction from the null hypothesis. There was no significant effect of large lobsters on the shelter choice of large conspecifics $(p>0.05)$, indicating that while small lobsters avoided large lobsters, large lobsters did not avoid small lobsters. However, there was a non-

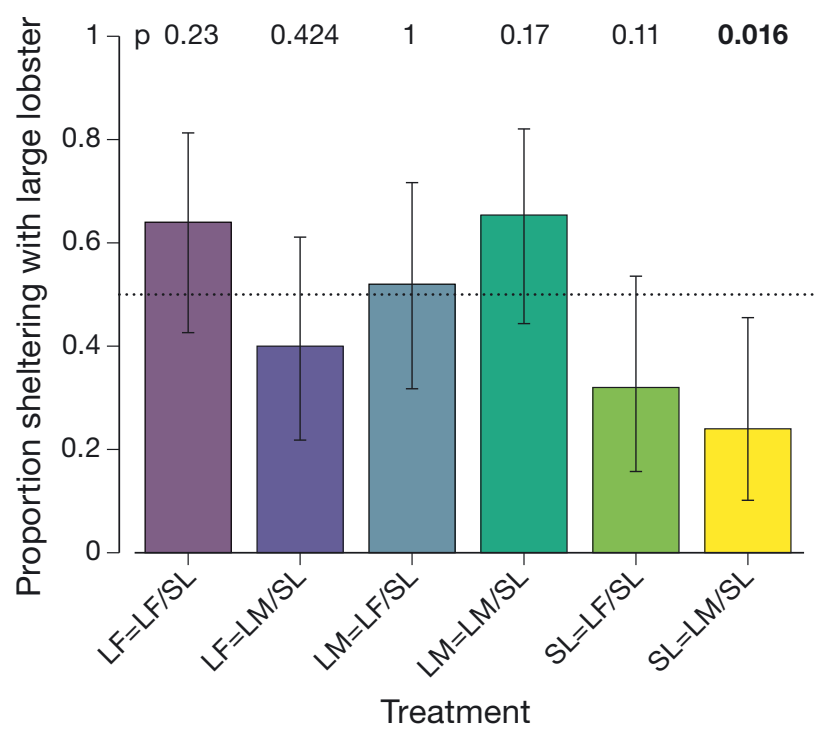

Fig. 3. Average proportion of focal lobsters sheltering with the large stimulus lobster in the aquaria trials, with $95 \%$ confidence intervals and p-values, calculated from the binomial test of given proportions (Wilson 1927). See Table 1 for treatment combinations. Dashed line: $50 \%$ proportion; bold denotes significance at $95 \%$ confidence limit 
significant tendency for large animals of the same sex to cohabit, with an $18 \%$ increase in large males cohabiting in trials (Fig. 3; LM $=\mathrm{LM} / \mathrm{SL}, \mathrm{p}=0.17$ ), and a $14 \%$ increase in large females cohabiting in trials (Fig. 3; LF $=\mathrm{LF} / \mathrm{SL}, \mathrm{p}=0.23$ ).

\subsection{Seeding experiment}

Each treatment was fished a total of 39 times over the 3 nights. Eight pairs of pots were removed due to compromised catches, leaving 31 paired pot lifts. These pots captured a total of 934 lobsters over the 3 nights, of which 895 had a CL of $80 \mathrm{~mm}$ or less (range: 32.3-80 $\mathrm{mm} \mathrm{CL}$; mean: $59.1 \mathrm{~mm} \mathrm{CL}$ ).

There were significantly ( $p<0.001$; Table 2 ) fewer small lobsters captured in the seed pots $($ mean $=$ 10.74 pot $^{-1}$ ), compared with the control pots (mean: 18.13 pot $^{-1}$ ). Across the 31 paired pot lifts, the mean $\alpha_{S}$ was 0.73 ( \pm 0.348$)$, which equates to a $27 \%$ reduction in the catchability of these pots. There was no significant difference in the proportions of small males and small females captured in the seeded pots $(p=0.51$; mean females: $32.7 \%$, means males: $34.9 \%$ ).

The greatest biomass was recorded in the control pots, with the seeded pots capturing on average almost half the biomass of the control pots (Fig. S2). This indicates that the majority of the seeded pots did not reach their upper biomass limits, despite these pots being seeded with a large lobster.

\subsection{Survey data}

In total, 1204 pot lifts were used in the analysis. Of those, 536 caught no large lobsters, 374 caught one or more large males, 154 caught one or more large females, and 140 caught at least one large male and one large female (Fig. 4). The pots captured a total of 1345 immature lobsters (394 females and 951 males),

Table 2. Paired $t$-test results of the field experiment data. Pot type: comparison of catch rates of small lobsters in the seeded and control pots; sex: comparison of the portions of males and females captured in the seeded pots. Bold denotes significance at $95 \%$ confidence limit. Note that all data has been square root transformed

\begin{tabular}{|lrrcrc|}
\hline & $\begin{array}{c}\text { Mean } \\
\text { difference }\end{array}$ & $95 \%$ CI & df & $t$ & p \\
\hline Pot type & 1.107 & $0.520-1.693$ & 30 & 3.857 & $<\mathbf{0 . 0 0 1}$ \\
Sex & -0.058 & $-0.234-0.118$ & 30 & -0.667 & 0.51 \\
\hline
\end{tabular}

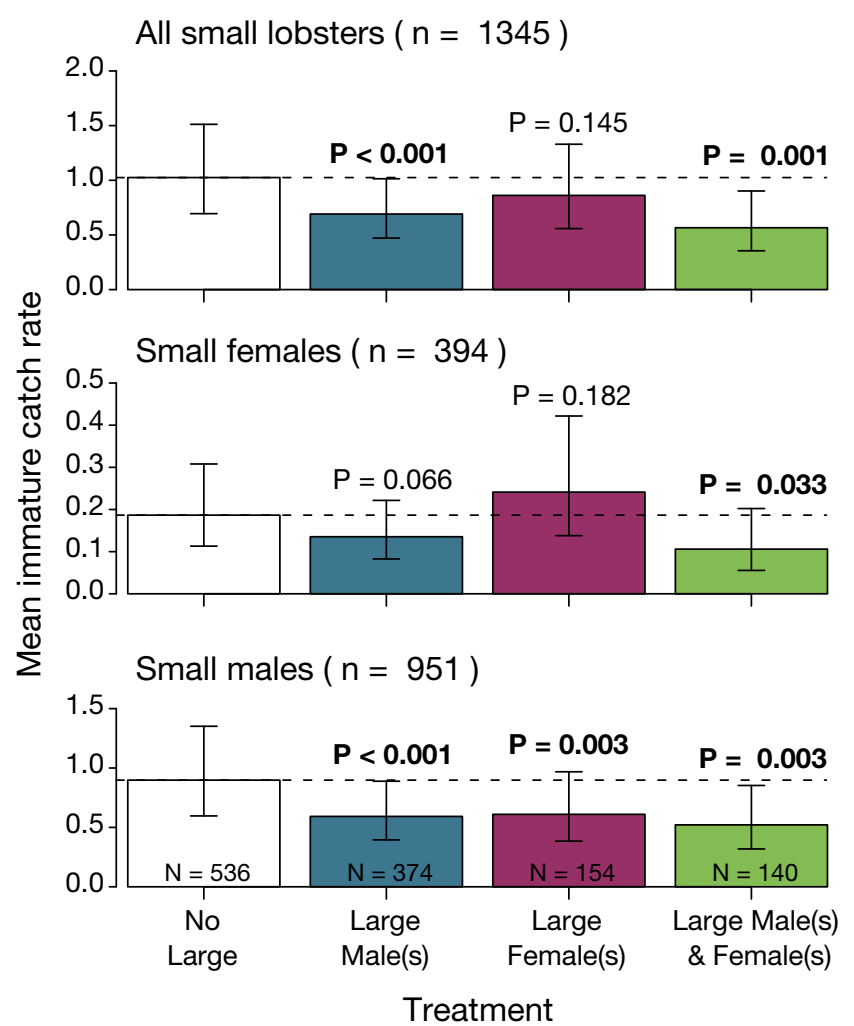

Fig. 4. Modelled mean catch rates, 95\% confidence intervals and $\mathrm{p}$-values of small immature lobsters (males and females [all], females only [females], and males only [males]), in each treatment (pots that captured no large animals [no large], one or more large males [large males(s)], one or more large females [large female(s)] calculated from generalised additive models fitted to the independent field survey data.

Bold denotes significance at $95 \%$ confidence limit

with a mean CL of $72.0 \mathrm{~mm}$ (range: $30.6-80 \mathrm{~mm}$ ) (Fig. 4).

Pots containing one or more large males caught significantly fewer small lobsters than pots with no large lobsters present (Fig. 4), with the catchability of small animals reduced by $32.9 \%$ in these pots ( $<<0.001$; Table 3). The effect was most significant for small males, with catchability reduced by $34.5 \%(\mathrm{p}<0.001)$, while the catchability of small females was only reduced by $27.8 \%(p=0.066$; Table 3$)$. There was no significant difference between the catch rate of immature lobsters in pots containing one or more large female lobsters and those without large lobsters ( $\mathrm{p}=$ 0.145 ; Table 3). However, when the catches of small males and females were modelled separately, pots containing large females caught fewer small males $(p=0.003)$ than pots with no large lobsters, with small male catchability reduced by $34.8 \%$ in these pots (Table 3). Conversely, pots with large females captured $28.9 \%$ more small females; however, this effect 
Table 3. Mean catch rates of small lobsters in each treatment, calculated from generalised additive models fitted to the independent field survey data. Treatment: categorization of the pot based on whether large lobsters were present or not-no large: no large animals present; large male(s): one or more large males present large female(s): one or more large females present; large male(s) + large female(s): both one or more males and one or more females present. $\alpha_{\mathrm{T}}$ : catchability scalar of each treatment $(\mathrm{T})$. Percent change in $q$ : the resulting change in catchability due to the scalar. Bold denotes significance at $95 \%$ confidence limit

\begin{tabular}{|lcccccc|}
\hline & $\begin{array}{c}\text { Mean catch } \\
\text { rate }\left(C_{\mathrm{T}}\right)\end{array}$ & $\mathrm{SE}$ & $\mathrm{p}$ & $\alpha_{\mathrm{T}}$ & $\begin{array}{c}\text { Change } \\
\text { in } q(\%)\end{array}$ \\
& & & & & & \\
\hline All undersized lobsters & & & & & & \\
$\quad$ No large & 1.030 & 0.205 & & 1.0 & \\
Large male(s) & 0.691 & 0.136 & $<\mathbf{0 . 0 0 1}$ & $\mathbf{0 . 6 7 1}$ & $\mathbf{- 3 2 . 9}$ \\
Large female(s) & 0.842 & 0.188 & 0.145 & 0.817 & $\mathbf{- 1 8 . 3}$ \\
Large male(s) + large female(s) & 0.573 & 0.137 & $\mathbf{0 . 0 0 1}$ & $\mathbf{0 . 5 5 6}$ & $\mathbf{- 4 4 . 4}$ \\
Female undersized lobsters & & & & & \\
$\quad$ No large & 0.187 & 0.048 & & 1.0 & \\
Large male(s) & 0.135 & 0.034 & 0.066 & 0.722 & -27.8 \\
Large female(s) & 0.241 & 0.069 & 0.182 & 1.289 & 28.9 \\
Large male(s) + large female(s) & 0.106 & 0.035 & $\mathbf{0 . 0 3 3}$ & $\mathbf{0 . 5 6 7}$ & $\mathbf{- 4 3 . 3}$ \\
Male undersized lobsters & & & & & \\
$\quad$ No large & 0.907 & 0.190 & & 1.0 & \\
Large male(s) & 0.594 & 0.124 & $\mathbf{0 . 0 0 1}$ & $\mathbf{0 . 6 5 5}$ & $\mathbf{- 3 4 . 5}$ \\
Large female(s) & 0.591 & 0.140 & $\mathbf{0 . 0 0 3}$ & $\mathbf{0 . 6 5 2}$ & $\mathbf{- 3 4 . 8}$ \\
Large male(s) + large female(s) & 0.533 & 0.134 & $\mathbf{0 . 0 0 3}$ & $\mathbf{0 . 5 8 8}$ & $\mathbf{- 4 1 . 2}$ \\
\hline
\end{tabular}

was not significant at the $95 \%$ confidence limit ( $p=0.182$; Table 3). Pots which captured both large males and females caught significantly fewer small lobsters $(p=0.001)$ than pots with no large animals, reducing small lobster catchability by $44.4 \%$ : females by $43.3 \%$ ( $p=0.033)$ and males by $41.2 \%$ ( $p=0.003$; Table 3$)$.

\subsection{Large lobster catch rate}

The mean catch rate of large $(\geq 100 \mathrm{~mm} \mathrm{CL})$ male and female lobsters ( $p<0.001$; Table 4 ) varied significantly between years. Following the first series of management changes (Fig. 5), the mean catch of large females significantly increased from around 0.1 lobsters pot $^{-1}$ to around 0.3 in the late 1990 s. It then decreased again in the early 2000s to around 0.2 pot $^{-1}$ before significantly increasing in the late 2000s following the second series of man-

Table 4. ANOVA results of generalised linear model of mean number of large female and male lobsters ( $\geq 100 \mathrm{~mm}$ ) caught per pot from $1992-2020$, as a function of year and location. Bold denotes significance at $95 \%$ confidence limit

\begin{tabular}{|lccccccc|}
\hline & \multicolumn{3}{c}{ Large females } & & \multicolumn{3}{c|}{ Large males } \\
\cline { 2 - 3 } & LR Chisq & df & $\operatorname{Pr}(>$ Chisq) & & LR Chisq & df & $\operatorname{Pr}(>$ Chisq $)$ \\
\hline Location & 520.49 & 4 & $\mathbf{< 0 . 0 0 1}$ & & 149.82 & 4 & $<\mathbf{0 . 0 0 1}$ \\
Year & 1007.34 & 28 & $\mathbf{< . 0 0 1}$ & & 1318.61 & 28 & $<\mathbf{0 . 0 0 1}$ \\
\hline
\end{tabular}
agement changes (Fig. 5). Large female catch rates peaked at 1.06 pot $^{-1}$ in 2014 and have since stabilised at around 0.5 pot $^{-1}$ in the late 2010s (Fig. 5).

There was an initial increase in large male catch rates during the first set of management changes, from $<0.01$ to around 0.17 lobster pot $^{-1}$ (Fig. 5). However, catch rates gradually decreased again from 1994-2000, and stayed relatively low at

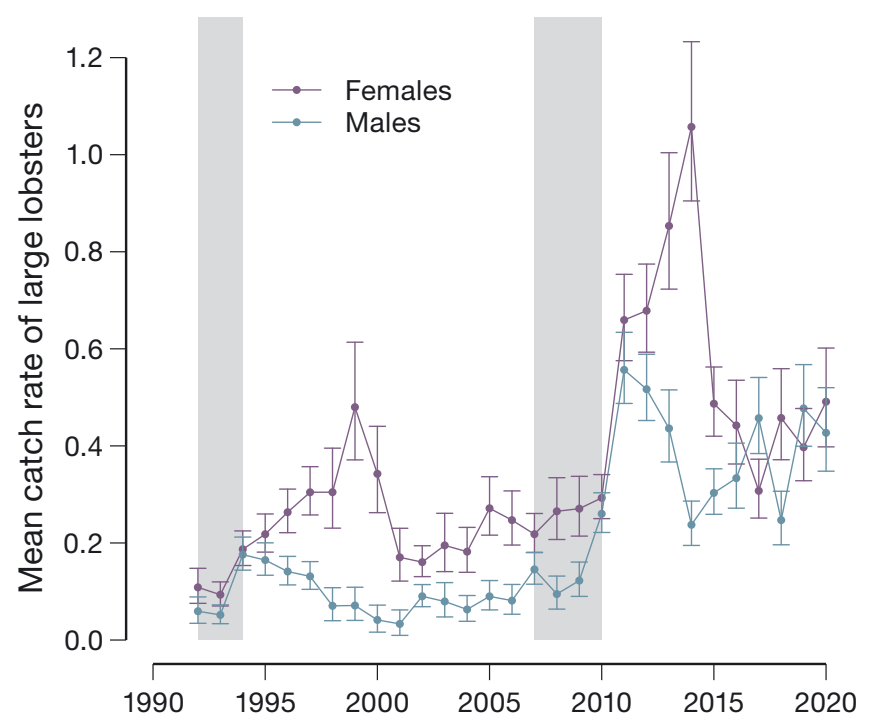
around 0.1 pot $^{-1}$ for most of the 2000s. Following the second series of management changes, however, mean catch rates of large males significantly increased to approximately 0.5 pot $^{-1}$ in 2014 , averaging 0.4 pot $^{-1}$ over the late 2010 s.

Fig. 5. Mean catch per unit effort, with $95 \%$ confidence intervals, of large lobsters (carapace length $\geq 100 \mathrm{~mm}$ ) during independent breeding stock surveys conducted by DPIRD, from 1992-2020. Shaded columns denote significant changes in the management of the fishery. The first series of management changes occurred between 1992 and 1994, and included effort reduction, the introduction of a maximum size limit for females, and protection for reproductive females (setose) (de Lestang et al. 2016). The second series of significant management changes occurred between 2007 and 2010, and included major effort reduction and culminated in the transfer to a quota-managed fishery (de Lestang et al. 2016) 


\section{DISCUSSION}

This study has demonstrated that the catchability of small, immature Panulirus cygnus is reduced by the presence of large conspecifics, and that this effect varies with sex and season. Cohabitation of small lobsters was reduced in shelters containing large lobsters, pots seeded with large females had reduced catch rates compared with control pots, and pots which captured large lobsters in the field generally had lower catch rates of small lobsters compared with pots without large lobsters present. Large lobsters showed no significant cohabitation preference in the aquaria trials, indicating that while large lobsters can deter small lobsters, small lobsters do not appear capable of deterring large. Large males had the greatest effect, reducing cohabitation and catch rates of small lobsters by around 30\% (26-33\%) in both the aquaria and the field surveys. Although the effect of large males was not tested in the seeding experiment, based on the significant effect of large females, it is likely that one existed. The effect of large females was more complex than males and varied seasonally. Large females reduced cohabitation of small animals in the aquaria (by 14\%), and the catchability of small animals in the pot seeding experiment (by $27 \%$ ), both of which were conducted during the mating season. However, in the field surveys, conducted during the spawning season, large females continued to reduce the catchability of small male lobsters (by $35 \%$ ) but did not reduce catchability in small females. While deterrent effects have been observed in some lobster and decapod species (Miller 1990, Frusher \& Hoenig 2001, Ihde et al. 2006), this study provides, for the first time, conclusive evidence of intraspecific catchability interactions in $P$. cygnus. Conspecific-related catchability should be a critical consideration when interpreting the results of pot-based surveys, which are commonly used in stock assessment models, assessments of no-take zones, fishery closures, and habitat association studies. These interactions are an especially important consideration when interpreting time-series CPUE from the P. cygnus fishery, as analysis of historical catch data indicates that there have been significant variations in the catch rates of large lobsters in this fishery over the past $29 \mathrm{yr}$.

The results of this study provide evidence to indicate that large lobsters deter smaller lobsters from entering pots; however, the mechanisms behind this deterrence are still unknown. Pots with large lobsters present are likely to reach their upper biomass limits (i.e. become saturated) at lower abundances than those without large lobsters, purely owing to the increased biomass of larger lobsters. However, this does not appear to be the sole cause of the reductions recorded within this study. Reduced catch rates of smaller lobsters in the seeding experiment were observed across a range of total pot densities, not just in the more densely inhabited pots. Furthermore, when the biomass of lobsters was compared between the 2 treatments, those with a seeded large lobster had, on average, almost half the biomass of those without a seeded large lobster. It is therefore likely that, in addition to any possible pot saturation effects, large lobsters specifically act as deterrents to smaller lobsters.

Due to their communal den sharing and perceived gregarious nature, spiny lobsters are not generally considered antagonistic or aggressive; however, aggressive behaviours have been observed in several species (Atema \& Cobb 1980, MacDiarmid 1989, Shabani et al. 2009, Hamasaki et al. 2018). While there has been very little research on behavioural interactions between adult P. cygnus, Cobb (1981) did observe aggressive interactions between adults related to den sharing, which often resulted in one lobster leaving the den. Additionally, spiny lobsters are known to use chemical cues to facilitate aggregations, detect predators, and avoid injured or diseased conspecifics (Berger \& Butler 2001, Horner et al. 2006, Candia-Zulbarán et al. 2015). In the absence of other cues, urine-borne signals alone have been shown to successfully induce avoidance behaviours in $P$. argus, causing the submissive lobster, usually the smaller animal, to move to a nearby shelter, and even suppressing appetitive responses to food odours (Shabani et al. 2009). All 3 studies described in this paper were designed to enable large lobsters the use of both physical and chemical attributes; it is, therefore, possible that both aggressive physical behaviours and chemical signalling are responsible for the deterrent effect of large $P$. cygnus.

Deterrent effects in the aquaria were observed only in large lobsters; small lobsters had no effect on the cohabitation of large individuals. Because lobsters are free moving in the field, it can be problematic to conclude that reductions in catch rates of small lobsters are the result of small lobsters avoiding large lobsters and not the result of large lobsters avoiding small. This study provides evidence that small lobsters do not deter large lobsters, and therefore pots containing large animals are likely to have reduced catchability for small animals. However, deterrent effects of small lobsters were only tested with a single small lobster, and many small lobsters may have yielded different results (Ratchford \& Eggleston 1998). 
No difference was expected in the effect of large $P$. cygnus on small males and small females - a key assumption of the aquaria trials in which small males and females were not differentiated. This assumption was supported by the results of the seeding experiments, in which there was no significant difference in the reduction of small male and small female catch rates in pots seeded with large females. However, in the field surveys, the presence of large lobsters affected small males and females differently. The magnitude of the large male effect was similar for small males and females, reducing catches by 34.51 and $27.81 \%$ respectively; however, the effect was only significant in small males. While large males may affect small males and females differently, considerably fewer small female lobsters were captured in the field surveys (394 females compared with 951 males), which may account for the lack of significance in the large male deterrent effect. Conversely, the effect of large females was considerably different for small males and small females. While there was no significant effect of large females on the combined catch rate of small lobsters, when differentiated by sex, catches of small males were significantly reduced by $35 \%$, while catches of small females were $29 \%$ greater (although this difference was not significant).

The variation in the effect of large females may be related to seasonality. It is very likely that over the timeframe of the 3 studies, large reproductive female P. cygnus transitioned across 2 distinct reproductive stages: mating and spawning. Due to the protracted nature of $P$. cygnus reproduction, catches of females with tar spots (spermatophores) are observed from early June, while spawning does not begin until midSeptember, peaking between early October and midNovember (de Lestang et al. 2016). The aquaria trials and seeding experiments were conducted between June and early September, during the mating season, while the field surveys occurred during the spawning season, between mid-September and November. Of the 418 large females captured in the field surveys, only 5 had not mated, over $50 \%$ had visibly ripe ovaries (Melville-Smith \& de Lestang 2005), and 28.7\% were already carrying eggs. Although the large females used in the pot seeding experiment had also mated, they were earlier in their reproductive cycle, with only approximately $10 \%$ of the mature female population carrying eggs at this time of the year (de Lestang et al. 2016), and were likely still weeks/ months from spawning. Reproductive females, therefore, are likely to have experienced hormonal changes related to ovary maturation over the time- frame of this study. These hormonal changes may be responsible for the changes in the large female effect. While large females deter both small males and females during the mating season, ovigerous females, or females close to egg extrusion, no longer had a deterrent effect on small females. This is consistent with previous research which found the inhibitory effect of large female Jasus edwardsii to be highly seasonal, significantly reducing the catch rates of small lobsters just before the mating season but not later in the year post-spawning (Ihde et al. 2006).

During the spawning season, large females may have attracted small females, with greater catch rates of small female lobsters in pots also containing large female lobsters. As with the deterrent effect of large males, the attraction effect between large and small females in the field surveys was not significant at the $95 \%$ confidence limit. Again, low numbers of small females may account for this. There was also evidence for an attraction effect in the aquaria trials, where large lobsters of the same sex showed some tendency, although not significant, to cohabit. Attraction between spiny lobsters has been well documented (Ratchford \& Eggleston 1998, Nevitt et al. 2000); however, the majority of previous research has concluded that attraction between conspecifics is independent of lobster size and sex (Zimmer-Faust et al. 1985, Horner et al. 2006), and seasonal variation in conspecific attraction has not been investigated. This study found evidence of possible attraction effects between large and small female lobsters during the spawning season and between large lobsters of the same sex during the mating season, indicating both size-sex and seasonal components. In addition, previous work has focussed on den selection and cohabitation, while the implications for pot catchability have been less well studied. For the first time, this study has provided evidence that an attraction effect between large and small female $P$. cygnus may result in increased catches of small females at certain times of the year. These results are, however, inconclusive and require further assessment.

If the effect of large females on the catchability of smaller animals varies across the reproductive season, the reproductive state of large females must be a key consideration when interpreting catch data. Breeding stock surveys are often timed to coincide with egg-bearing periods; however, the exact timing of the reproductive cycle can vary from season to season. Timing of mating and ovarian development have been correlated with water temperatures in some Panulirus species (Matsuda et al. 2002, Vega Velázquez 2003), and water temperature is known to 
impact the timing of moulting to setose and embryonic development in P. cygnus (Melville-Smith \& de Lestang 2006). Interannual variations in water temperature are therefore likely to cause variations in the timing of breeding and spawning in P. cygnus, and are likely to be exacerbated under future climate change predictions. How lobster catchability relates to reproduction must be understood to ensure the continued accuracy and comparability of stock surveys over time.

Because conspecific-related catchability in P. cygnus appears to be size- and sex-specific, it will be especially problematic for measuring relative abundance if population demography changes through time or space. Fewer large lobsters, due to sizespecific targeted fishing pressure, could increase the relative catchability of smaller animals, which may be interpreted as increased recruitment (Frusher et al. 2003). Conversely, management changes which increase the abundance of larger animals will result in small lobsters increasingly being underrepresented in catch data, and recruitment may be perceived to be declining. The results of this study indicate that management changes in the $P$. cygnus fishery over the past $29 \mathrm{yr}$ have resulted in large variations in population demographics. Observed variations in large lobster catch rates during standardised fisheryindependent surveys are indicative of changes in large lobster abundance, suggesting that the demography of the fishery has experienced both decreases and increases in large lobster abundance. There was an increase in catch rates of large lobsters following a series of significant management changes between 1992 and 1994, which included an effort reduction and, importantly, the introduction of a maximum size limit for females and protection of reproductive females. This increase was more significant and persistent in females than in males, likely due to the greater level of protection afforded to adult female lobsters compared with males by the new regulations. Mean catch rates of large male and female lobsters increased again following the second series of management changes between 2007 and 2010, which included major effort reduction and adoption of maximum economic yield as a management target and culminated in the transfer to a quota managed fishery (de Lestang et al. 2016). These variations in large lobster abundance over the past $29 \mathrm{yr}$ are likely to have significantly affected the catchability of smaller animals, and this should be accounted for when modelling abundance from time series catch rate data.

In addition to the long-term trends in large lobster CPUE, there were significant inter-annual variations between years. Despite these surveys being standardised for bait, location, month, and fishing gear, some of this variation was so extreme that it is unlikely to be a true reflection of variation in abundance. For example, CPUE of large males doubled, from 0.3-0.6 pot $^{-1}$, and large females more than doubled, from 0.3-0.7 pot ${ }^{-1}$, between 2010 and 2011. It is very unlikely that the abundance of these older animals doubled within 12 mo. It is more plausible that other factors affecting the catchability of these animals caused these significant variations. The catchability of $P$. cygnus has been significantly correlated with environmental factors such as swell (Srisurichan et al. 2005) and water temperature (Morgan 1974), as well as biological factors such as moult (Morgan 1974) and reproductive stage (Waddington et al. 2005). Changes in catchability caused by variations in these factors are likely to cause variations to catch rates, both between years as well as between months within years. How variations in the catchability of large animals affect catch rates, and to what extent this affects the catchability of smaller lobsters, requires further investigation.

Studies of the effects of fishing pressure and notake marine reserves on crustaceans often use undersized abundances, calculated from CPUE, to compare the suitability of control (fished) sites to those within a no-take reserve (Iacchei et al. 2005, Kay et al. 2012). As under-sized crustaceans are not subject to fishing pressure, the ratio of legal-sized to under-sized animals is sometimes used as an indication of the impact of protected areas. However, if increased abundances of large lobsters inside closures reduced the catchability of the smaller animals, this will skew the ratio towards large animals, thereby artificially increasing the perceived positive effects of the closure.

Similarly, studies which rely on pot-based data to investigate habitat use also need to consider conspecific catchability relationships. For example, Bellchambers et al. (2010) concluded that large and small $P$. cygnus have different habitat assemblage associations, as mean lobster CL was larger in areas with Ecklonia sp. and smaller in areas dominated by sponges. However, the authors noted that conspecific pot interactions may confound these conclusions; and indeed, the results of the present study suggest that the reported absence of small lobsters in the Ecklonia sp. habitat may be a result of reduced catchability of these animals caused by the greater numbers of large animals in these habitats. So while their results indicate that large lobsters were more abundant in Ecklonia sp., inferences about the habitat use of smaller lobsters should be made with con- 
sideration for the impacts of behavioural catchability. Without considering, and ideally accounting for, the demonstrated conspecific-induced variations in catchability, management and researchers may come to erroneous conclusions about population abundances and distributions.

Correction factors, or selectivity curves (see Frusher et al. 2003 for example), could be applied to catch rate data to compensate for the effect of large lobsters in pots. Calculation of such corrections would require further research spanning greater temporal and spatial scales than the present study, to ensure it encapsulates seasonal changes and to investigate whether correction factors need to be location- and/or population-specific. Future research should also investigate whether multiple large lobsters result in an amplified deterrent effect. These models would need to account for other environmental and biological factors that may cause variation in catchability, such as swell, temperature, and moult cycles (Morgan 1974, Srisurichan et al. 2005, Feenstra et al. 2014). While the field surveys were standardised for the moon phase, swell and temperature are harder to control for and will likely vary considerably from day to day and month to month. If external stimuli affect large and small lobster catchability differently, as may be the case for swell (Srisurichan et al. 2005), they are likely to have confounded the results of the field surveys. Further research should be undertaken in this area to disentangle the impacts of both environmental and biological factors on the catchability of $P$. cygnus.

\section{CONCLUSIONS}

This study demonstrated, for the first time, that large male and female Panulirus cygnus reduce the catchability of smaller conspecifics. In aquaria trials and field surveys, large male $P$. cygnus significantly reduced the catchability of smaller immature lobsters, by approximately $30 \%$. This effect was consistent throughout the study, while the effect of large females varied seasonally. During the mating season, large female $P$. cygnus reduced shelter selection in the aquaria, and catchability in the field, in both small male and female lobsters by $14-27 \%$. However, during the breeding season, large females reduced the catchability of small males by approximately $35 \%$, but may have increased the catchability of small females by $29 \%$. These relationships need to be understood and accounted for when using catch data to calculate abundance and model population demography, which is common in both lobster fisheries and ecological studies. This is especially important when interpreting time series catch rates from the $P$. cygnus fishery, as the catch rates, and likely the abundance, of large lobsters has varied considerably over the past $29 \mathrm{yr}$. Without understanding these relationships, pot-based surveys may lead to erroneous conclusions, which in turn may well lead to poor management decisions.

Acknowledgements. The authors acknowledge the traditional custodians of the land upon which this research took place, the Whajuk Noongar people, the Yued Noongar people and the Amangu Noongar people, and pay our respects to their elders, past, present and emerging. The authors acknowledge the Fisheries Research and Development Cooperation (FRDC) for funding this research (2016-124). The authors thank the editor and reviewers for their valuable feedback and contributions to the manuscript. The authors thank the WAFMRL aquaculture team, especially Justin King and Sagiv Kolkovski, and Ivan Lightbody, for their help with the aquaria trials. Special thanks to Ben Hebiton for his help with the field experiments at Seven Mile Beach. Ben's expertise and extensive knowledge of the area were integral to the experiment, which could not have been undertaken without him. Also thank you to Rhys Allen for his help at Seven Mile. Thanks also to Brock Keymer who trialled the aquaria methods in a separate study. Particular thanks to Mark Rossbach and all associated DPIRD staff who have contributed to the annual western rock lobster independent stock survey. This research was carried out while the primary author was in receipt of an Australian Government Research Training Program (RTP) Scholarship at The University of Western Australia

\section{LITERATURE CITED}

Addison JT (1995) Influence of behavioural interactions on lobster distribution and abundance as inferred from potcaught samples. ICES Mar Sci Symp 199:294-300

Addison JT, Bannister RCA (1998) Quantifying potential impacts of behavioural factors on crustacean stock monitoring and assessment: modeling and experimental approaches. In: Jamieson GS, Campbell A (eds) Proceedings of the North Pacific Symposium on Invertebrate Stock Assessment and Management. NRC Research Press, Nanaimo, p 167-177

Atema J, Cobb J (1980) Social behavior. In: Cobb J, Phillips B (eds) The biology and management of lobsters: physiology and behavior. Elsevier, New York, NY, p 409-450

* Babcock RC, Phillips JC, Lourey M, Clapin G (2007) Increased density, biomass and egg production in an unfished population of western rock lobster (Panulirus cygnus) at Rottnest Island, Western Australia. Mar Freshw Res 58:286-292

* Barrett N, Buxton C, Gardner C (2009) Rock lobster movement patterns and population structure within a Tasmanian marine protected area inform fishery and conservation management. Mar Freshw Res 60:417-425

* Bellchambers LM, Evans SN, Meeuwig JJ (2010) Abundance and size of western rock lobster (Panulirus 
cygnus) as a function of benthic habitat: implications for ecosystem-based fisheries management. Mar Freshw Res 61:279-287

Bellchambers LM, How J, Evans S, Pember M, de Lestang S, Caputi N (2017) Ecological assessment report: western rock lobster resource of Western Australia. Fisheries Research Report No. 279. Department of Fisheries, Perth

Berger DK, Butler MJ (2001) Octopuses influence den selection by juvenile Caribbean spiny lobster. Mar Freshw Res 52:1049-1053

Candia-Zulbarán RI, Briones-Fourzán P, Lozano-Álvarez E, Barradas-Ortiz C, Negrete-Soto F (2015) Caribbean spiny lobsters equally avoid dead and clinically PaV1infected conspecifics. ICES J Mar Sci 72:i164-i169

Caputi N, de Lestang S, How J, Trinnie F, Fletcher W (2018) Ecosystem-based fisheries management (or 'triple bottom line') assessments of the western rock lobster resource: Is there an optimal target for fishing? Mar Policy 94: 264-274

Childress MJ, Herrnkind WF (2001) The guide effect influence on the gregariousness of juvenile Caribbean spiny lobsters. Anim Behav 62:465-472

Clarke KR, Warwick RM (1994) Change in marine communities: an approach to statistical analysis and interpretation. Plymouth Marine Laboratory, Plymouth

Cobb JS (1981) Behaviour of the Western Australian spiny lobster, Panulirus cygnus George, in the field and laboratory. Aust J Mar Freshwater Res 32:399-409

Cox C, Hunt JH (2005) Change in size and abundance of Caribbean spiny lobsters Panulirus argus in a marine reserve in the Florida Keys National Marine Sanctuary, USA. Mar Ecol Prog Ser 294:227-239

Crawley MJ (2002) Statistical computing - an introduction to data analysis using S-plus. John Wiley \& Sons, New York, NY

de Lestang S (2018) Could warming oceans and increased lobster biomass rates be affecting growth rates in Australia's largest lobster fishery? Bull Mar Sci 94: 1055-1075

de Lestang S, Caputi N, How J (2016) Resource assessment report: western rock lobster resource of Western Australia. Western Australian Marine Stewardship Council Report Series 9. Department of Fisheries, Perth

de Lestang S, Penn JW, Caputi N (2018) Changes in fishing effort efficiency under effort and quota management systems applied to the Western Australian rock lobster fishery. Bull Mar Sci 94:1077-1094

Feenstra J, McGarvey R, Linnane A, Punt AE, Bean N (2014) Environmental influences on daily commercial catch rates of South Australia's southern rock lobster (Jasus edwardsii). Fish Oceanogr 23:362-374

Frusher SD, Hoenig JM (2001) Impact of lobster size on selectivity of traps for southern rock lobster (Jasus edwardsii). Can J Fish Aquat Sci 58:2482-2489

* Frusher SD, Hoenig JM, Gardner C (2003) Have changes in selectivity masked recruitment declines in crustacean trap fisheries? Fish Res 65:467-474

Gaughan DJ, Santoro K (eds) (2018) Status reports of the fisheries and aquatic resources of Western Australia 2017/18. Department of Primary Industries and Regional Development, Perth

Hamasaki K, Sugiyama A, Jinbo T, Murakami K (2018) The influence of male size on competitive mating success in the Japanese spiny lobster Panulirus japonicus (von Siebold, 1824) (Decapoda: Palinuridae): implications for broodstock management techniques. J Crustac Biol 38: 393-400

*Horner AJ, Nickles SP, Weissburg MJ, Derby CD (2006) Source and specificity of chemical cues mediating shelter preference of Caribbean spiny lobsters (Panulirus argus). Biol Bull (Woods Hole) 211:128-139

Hunt JH (2008) Status of the fishery for Panulirus argus in Florida. In: Phillips B, Kittaka J (eds) Spiny lobsters: fisheries and culture. Fishing News Books, Oxford, p 189-199

* Iacchei M, Robinson P, Miller KA (2005) Direct impacts of commercial and recreational fishing on spiny lobster, Panulirus interruptus, populations at Santa Catalina Island, California, United States. NZ J Mar Freshw Res 39:1201-1214

Ihde TF, Frusher SD, Hoenig JM (2006) Do large rock lobsters inhibit smaller ones from entering traps? A field experiment. Mar Freshw Res 57:665-674

Kay MC, Lenihan HS, Kotchen MJ, Miller CJ (2012) Effects of marine reserves on California spiny lobster are robust and modified by fine-scale habitat features and distance from reserve borders. Mar Ecol Prog Ser 451:137-150

* MacDiarmid AB (1989) Moulting and reproduction of the spiny lobster Jasus edwardsii (Decapoda: Palinuridae) in northern New Zealand. Mar Biol 103:303-310

*MacDiarmid AB (1994) Cohabitation in the spiny lobster Jasus Edwardsii (Hutton, 1875). Crustaceana 66:341-355

* Matsuda H, Takenouchi T, Yamakawa T (2002) Effects of photoperiod and temperature on ovarian development and spawning of the Japanese spiny lobster Panulirus japonicus. Aquaculture 205:385-398

* Melville-Smith R, de Lestang S (2005) Visual assessment of the reproductive condition of female western rock lobsters (Panulirus cygnus). NZ J Mar Freshw Res 39:557-562

* Melville-Smith R, de Lestang S (2006) Spatial and temporal variation in the size at maturity of the western rock lobster Panulirus cygnus George. Mar Biol 150:183-195

Miller RJ (1989) Catchability of American lobsters (Homarus americanus) and rock crabs (Cancer irroratus) by traps. Can J Fish Aquat Sci 46:1652-1657

Miller RJ (1990) Effectiveness of crab and lobster traps. Can J Fish Aquat Sci 47:1228-1251

Miller RJ (1995) Catchability coefficients for American lobster (Homarus americanus). ICES Mar Sci Symp 199: 349-356

*Montgomery SS, Liggins GW (2013) Recovery of the eastern rock lobster Sagmariasus verreauxi off New South Wales, Australia. Mar Biol Res 9:104-115

Morgan GR (1974) Aspects of the population dynamics of the western rock lobster, Panulirus cygnus George. II. Seasonal changes in the catchability coefficient. Aust J Mar Freshwater Res 25:249-259

Nevitt G, Pentcheff ND, Lohmann KJ, Zimmer RK (2000) Den selection by the spiny lobster Panulirus argus: testing attraction to conspecific odors in the field. Mar Ecol Prog Ser 203:225-231

* Punt AE, Huang T, Maunder MN (2013) Review of integrated size-structured models for stock assessment of hard-to-age crustacean and mollusc species. ICES J Mar Sci 70:16-33

* Ratchford SG, Eggleston DB (1998) Size- and scaledependent chemical attraction contribute to an ontogenetic shift in sociality. Anim Behav 56:1027-1034

RStudio Team (2020) RStudio: integrated development for R. RStudio, Boston, MA

* Shabani S, Kamio M, Derby CD (2009) Spiny lobsters use 
urine-borne olfactory signaling and physical aggressive behaviors to influence social status of conspecifics. J Exp Biol 212:2464-2474

Srisurichan S, Caputi N, Cross J (2005) Impact of lunar cycle and swell on the daily catch rate of western rock lobster (Panulirus cygnus) using time series modelling. NZ J Mar Freshw Res 39:749-764

Tuffley EJ, de Lestang S, How J, Langlois T (2018) Methodological comparison for sampling populations of a commercially important rock lobster species. Bull Mar Sci 94: 1035-1054

Vega Velázquez A (2003) Reproductive strategies of the spiny lobster Panulirus interruptus related to the marine environmental variability off central Baja California, Mexico: management implications. Fish Res 65:123-135

Waddington K, Melville-Smith R, Walker D, Knott B (2005) Effect of reproductive state and sex on movement and food consumption of western rock lobster (Panulirus

Editorial responsibility: Stephen Wing,

Dunedin, New Zealand

Reviewed by: M. Childress, A. MacDiarmid and 1 anonymous referee cygnus) in a tank environment. NZ J Mar Freshw Res 39: 365-372

*Wickham H, François R, Henry L, Müller K (2020) dplyr: a grammar of data manipulation. $\mathrm{R}$ package version 0.8.5. https://CRAN.R-project.org/package=dplyr

Wilson EB (1927) Probable inference, the law of succession, and statistical inference. J Am Stat Assoc 22:209-212

Wood S (2017) Generalized additive models: an introduction with $R, 2^{\text {nd }}$ edn. CRC Press, Boca Raton, FL

Ziegler PE, Johnson CR, Frusher SD, Gardner C (2002) Catchability of the southern rock lobster Jasus edwardsii. II. Effects of size. Mar Freshw Res 53:1149-1159

Zimmer-Faust RK, Spanier E (1987) Gregariousness and sociality in spiny lobsters: implications for den habitation. J Exp Mar Biol Ecol 105:57-71

Kimmer-Faust RK, Tyre JE, Case JF (1985) Chemical attraction causing aggregation in the spiny lobster, Panulirus interruptus. Biol Bull (Woods Hole) 169:106-118

Submitted: October 22, 2020

Accepted: March 12, 2021

Proofs received from author(s): May 7, 2021 